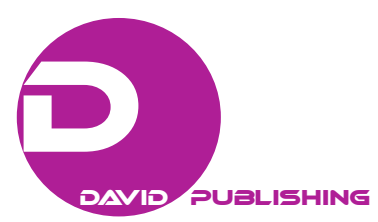

\title{
Construction of Network Legal Supervision Mode With Chinese Characteristics ${ }^{*}$
}

\author{
Ling Lin \\ East China University of Political Science and Law, Shanghai, China
}

\begin{abstract}
Localizing network legal supervision based on national conditions, legal traditions and the needs of economic and political development is the basis to manage and administrate the network by law. Adjusted to media convergence and the needs of network cultural industry development, China has made the lawmaking of media transform from practical service oriented management to functional oriented management of media. This strategy aims to prevent network medium risk effectively according to network communication regularity.
\end{abstract}

Keywords: Chinese characteristic, Network legal supervision mode, Network medium risk

With the rapid development of network technology and information communication technology, the division of labor, as well as the social functions of newspapers, radio and television, communication equipment and network industry has been changed. Media convergence forces the government to revise various kinds of laws and regulations formulated based on traditional media's one-dimensional function supervision. It also motivates the government to actively explore the legal path and method of media supervision in the time of Web 2.0. The openness, inclusiveness and universality nature of network media have turned the network into a basic media platform mixed with multiple types of media, which has produced some media like Internet newspapers, Internet television, Internet we-media and the cross-industry network integration application mode, such as Internet finance, Internet shopping and a lot more. With a huge volume of audience and strong interactivity, the network has become the most popular and influential public information platform. The network breaks through the industrial boundary and functional attributes of the traditional media, creates marginal media, micro media and we-media. Moreover, it breaks the traditional boundary between media, the social public sector, and the private sector, which issues a challenge to the traditional media law regulation and social management strategies.

The traditional media's orientation of social division of labor and public domain, construction of news content and communication effects makes the media a self-sufficient social sub-system. The government has effectively supervised the media operations and information dissemination according to the media's independent social space, the distinct social functions and the rigid demand coming from the news media occupation. However, the paths, methods, and effects of information dissemination have been changed by the network technology and information communication technology, which leads to dramatic changes in the basic

\footnotetext{
* The author wishes to record his deep sense of gratitude to Yi Xia, Communication Law Research Center, Department of Humanities, East China University of Political Science and Law; Xing Tong, Communication Department, College of Humanities and Social Science, George Mason University.

Ling Lin, Professor, Communication Law Research Center, Department of Humanities, East China University of Political Science and Law.
} 
attributes of network media, both endogenous and exogenous functions of the media appear the trend towards re-division of labor, and then re-convergence of media. There are multiple consequences triggered by this trend. Firstly, the public domain boundaries of the network media tend to be blurred, or even disappear. When the country is authorized by law to protect media's information dissemination, like using the right of freedom of speech, the right of public opinion supervision and the right of social participation, the media will focus on and participate in the social and public affairs, then succeed in separating private information dissemination activities built upon interpersonal communication and group communication from the field of mass communication, which has made the media the most important public area in modern society. However, this kind of the legal authorization would not necessarily turn to the media's the public area, because it also needs the help of the traditional media's resources monopoly and the hegemony of speech so that it can divide the public's private discourse space from the media's public domain. In order to counterbalance and balance traditional media's resource monopoly and exclusive dissemination, the state also has authorized and protected the public's right to know, the right to access media, combined media public space and public private space, and formed the structural information communication network. However, as Internet we-media and Internet instant communication tools are in the border of the public and private spheres, we can judge and define its public property neither on the basis of media's social function, nor the content of the dissemination. Here, the traditional boundary of the public domain has been blurred and disappeared. Secondly, the network chain-style transmission has showed Domino propagation effects. Compared with "obvious transmission" of the traditional media, network media focus on and diffuse information in form of "potential transmission" (Yi \& Liu, 2010), extend the function of network interpersonal communication and form the communication mode of "core-periphery". On the one hand, the construction of interpersonal network has been continuing in we-media website and also further met the needs of instant communication between friends through instant information sharing. Meanwhile, it has met the interactive needs of taking and giving information based on the relatively stable relationship of "follow-being followed" formed by the sharing information. With the increasingly frequency usage of we-media, the stickiness of we-media to users has become stronger and stronger. The additional function of users' multi-lateral needs for Internet applications has been developed. The "indirect interpersonal network circle" built by traditional media based on strange audience has been broken through. On the other hand, considered the direction of information dissemination, whether we-media's subject (communicator) or we-media's object (receiver) is treated as the center, despite the different directions of information dissemination in node, they get information carried by other nodes together in the communication mode of "core-periphery". For example, the users of we-media like mirco-blog and we-chat can bring other nodes in their own information network by the methods of "followed" and "added as a friend", or become a node in the network of other key users and actively or passively construct their own information network by instant aggregation (Dai, 2011). In this case, the information dissemination of Internet media has appeared with may charactistics such as diversification of channels, non-direction of the information's flowing, etc. The network information sends out from any network node and moves forward along these network channels such as "media-etizens" (mass communication), "netizens-netizens" (interpersonal communication), and "the netizens - netizen groups" (group communication) and forms the chain-style network transmission. With multi-directions, complementary and alternative features, once one node appears to be the barriers of communication, other nodes will immediately fill the functional blank left by this node to ensure that information communication continue. Therefore, the traditional method of checking and filtering information 
by disturbing and blocking key communication links is difficult to have an effect on the management of chain-style network communication. For example, the Department of Internet Supervision has deleted network rumor, information about Internet infringement, but it can't immediately terminate the chain-style network transmission. The information may continue to spread in the network space automatically supported by other network nodes so that it can become the eternal, ineradicable "news".

Therefore, to build the network legal regulation must focus on attributes of network communication tools and the characteristics of public domain, coordinate the conflicts between Internet media and Internet communication tools, between network private space and public space, and between the network public power and private rights in order to protect the healthy development of network communication.

\section{Innovation the Mode of Network Media Legal Supervision}

China is actively exploring the mode of network legal media supervision. Based on China's economic structure transformation and the network's basic national condition that is the number of Chinese netizens has ranked No. 1 in the world, learning from the experience of network media's legal regulation in western countries, considering China's political system, economic industry structure, national strategic security and the existing legal content, the mode of network media legal regulation has been innovated, which will help to improve the level of legal regulation on network media and enhance the national cultural soft power in a full scale.

Firstly, to adopt unified mode of network media legal regulation and reduce the obstacles on the way of legal regulation made by the relative backwardness of network media's legal system. To realize the university of legal regulation on media is the general way for countries in the world, which has been proved in practice to be real and effective method of supervision. In 1934, American Telecommunication Act permitted FCC to supervise radio television and telecommunication. The Telecommunication Act in 1996 passed by the parliament ordered that FCC should start unified supervision on radio and television, telecommunication and Internet. In 2003, the UK produced Communication Bills, which set that the five former departments including Telecommunication Administration Bureau, Radio Communication Administration Bureau, Independent Television Committee, Radio Administration Bureau and Broadcasting Standard Committee were replaced by the newly-built, unified supervision agency-broadcasting communication office to make the uniform regulation on media. In 2008, the South Korea legally approved that a radio communication committee would be established and took the place of former Department of Information and Communication Committee of Radio to unify supervision on radio, television, and telecommunication ( $\mathrm{Li}, 2010)$.

The legal supervision of network media concerns with several fields including Criminal Law, Civil Law, Administrative Law, Economic Law, International law and so on, exceeded the scale adjusted by separate law. Therefore, it is necessary to make unified laws and rules of supervision on network media and uniform the content of supervision which once separately belonged to newspaper, radio and television and Internet. It cannot only avoid appearing blanks in legal supervision, but also save the cost of legal supervision and advance the efficiency of supervision. On the one hand, the network media's communication mode and commercial mode have been unceasingly innovated. The relationship of legal rights and duties between facilitator of network content and the owners of network media has been gradually blurred so that it is in dire need of laws and rules on regulation. On the other hand, as a tool of public opinion's regulation and network anti-corruption, the network we-media and network instant communication tools easily infringe citizens' right of privacy and also starve for the legal adjustment and authorization. Therefore, the innovation of the legal regulation mode 
must be made to promote the innovation of legal regulation's content and method. At present, the key points about unified legal regulation on China's network media include the following points. First, government regulators and network industry should further make a clear distinction between function and power. The government regulators can't interfere in the network industry's strategies and development. They can regulate network media only by law and policy and gradually separate the links of property rights and personnel matters with nation-owned communication cooperates represented by China Telecommunication, China Mobile, China Unicom to settle the problem of integration of government regulation with enterprises in network regulation. Second, to uniform network legal supervision dispersed in Ministry of Industry and Information Technology (MIIT), State Administration of Press, Publication, Radio, Film and Television, National Development and Reform Commission, State-owned Assets Supervision and Administration Commission, Ministry of Commerce and set up independent supervision organization affiliated to state department so as to reduce obstacles and functional wasting of legal supervision system to the innovation of network media.

Secondly, to deal with challenges from media convergence to legal supervision of network media and develop network media's functional supervision based on the division of network media's business. The network media's functional supervision focuses on the settlement of the problems such as non-unified standard of legal regulation produced by news communication business's diverging, overlapping and intersecting after media convergence, the legal gaps in supervision and so on. The key point is to deal with the problem of responsibility and standard in legal supervision.

To make unified supervision of content on network media with different attributes can avoid weakening supervision because of the blurring subjects of network media's legal supervision. For example, the communication of network we-media represented by blog, micro-blog and the group communication of network instant communication tools represented by QQ, Wechat have some a lot in common in the aspect of communication function. However, in the aspect of communication attribute, the network we-media belongs to mass communication and the circle of acquaintances and friends of network instant communication tools belongs to group communication. Both of them should apply to different standards of legal supervision. In fact, the communication effect of network instant communication tools never worse than blog and micro-blog. Therefore, it is necessary to uniform the subjects of network legal supervision and apply the unified standard of legal supervision to supervise network we-media and network instant communication tools. For another example, the network communication platform represented by QQ, micro-blog has more and more deeply realized the convergence of network media and communication tools, so that it is hard to meet the needs of development in network media (communication tools) by separate management. Therefore, we must learn from the experience of network media legal supervision aboard and follow the way of unified supervision. Considering Chinese network's political attributes, network development level and the social industrial structure, China can't manage network by just treating it as simple media like Singapore, neither can China manage network as communication tools, like Japan or Taiwan of China. Therefore, it is applicable to set out the strategy of step-by-step: from the view of long-term object of legal supervision, it should treat network media and network communication tools as the unified regulated objects and apply unified standard of legal regulation to regulate. In the view of short-term object of legal supervision, it should apply different kinds of legal supervision on network we-media and network communication tools.

Thirdly, redefine the rights of network writing and publishing and make staged decentralized legal regulation on network media. Interim Provisions on the Administration of Websites Covering News Business 
has distinctly ordered the qualification for network media to have the rights of writing and publishing. But, those rules based on traditional media have already been hard to meet the needs of network media's legal regulations. The so-called news writing means that the citizens with special ID (like journalists and reporters) do research of the details of public affairs and write it out as news. This activity concerns with social public domain and needs legal authorization. But the activity of netizens who write what they experience by themselves and what they think and upload it on the Internet belongs to the netizens' private domain and don't need legal authorization. However, if netizens specialize in writing public affairs that they never experience by themselves just like journalists, they will be restricted by law. The right of publishing means that news media have the right to publish journalists' or other's passages. In traditional society, the right is monopolizing right. But in the network environment, the technologies of linking and copying make the monopolizing right of publishing invalid. As the right of information communication is one of the basic network rights of netizens, it is feasible to properly reduce the scale defined by law of publishing right, which specially indicates that the right for one to first publish his own or other's passage and then upload it onto the Internet. To distinguish whether the message is first published or be copied will be the basic point to define each one's legal responsibilities.

To establish network media's staged decentralized legal supervision system in the base of redefinition of the right of network writing and the right of network publishing. Post-supervision and post-punishment are the world's popular network legal supervision system, which helps to balance the relationship between the development of network and the protection of netizens' rights. In the practice of network legal supervision, as some reasons like the easily-destroyed electronic evidence and separation of network crime (infringement)'s the occurring place and the ending place, post-supervision and post-punishment has resulted in less effective effect of supervision. It is good for improving the effect of supervision to transform government administrators' centralized supervision mode to decentralized supervision mode, define the relationship between rights (obligations) and duties of network communication objects and avoid the blank and overlapping of legal supervision. First, government administrators should authorize Internet Content Provider to approve network we-media and network instant communication tools, that is as long as the public apply to Internet Content Provider, then they get the rights of owning and using of network we-media and network instant communication tools. Besides, the government administrators should authorize Internet Content Provider to supervise network we-media and network instant communication tools, which could ease the burden of government supervision, increase the efficiency of supervision and make Internet Content Provider become the responsible object of network. Second, Internet Content Provider and network we-media and network instant communication tools build the commercial relationship as well as the relationship of supervising and being supervised. Internet Content Provider, who has already been authorized should carry out a full supervision of the other two's network activity. In this way, Internet Content Provider can not only practice the social public function of network supervision, but also face radical competition of the market and balance the conflicts of interests between network we-media and network instant communication tools in the network cultural market so as to avoid the problem of misusing the right of supervision to limit the right of free speech on network. Third, adopt technological method to define netizens' rights of writing and publishing and make a clear boundary between the right of freedom on network shared by netizens and the network obligation shouldered by netizens. Transform those netizens who misuse the right of free speech on network with the mentality of fluke to these netizens who consciously abide by the law. Guarantee the healthy development of network and promote the process of social democratization. 


\section{Construction of the Mode of Legal Supervision to Prevent Medium Risks}

The so-called medium risk, also named presented risk, means that most of the social risks in modern society is presented by behavior of media's information communication. The risks that general people feel are not the real social risks, but the one the media present. Therefore, the information of risks covered by the media constitutes the key source of social risks. In the mimetic environment, it is possible for media to arise "medium risks" actively or passively, which should be effectively prevented from occurring by government (Tuo, 2008). Any society exists problems and conflicts, which are settled by directly reforming the objective environment in traditional society, and by making difference on informatization environment in information society. Since informatization environment is not the photographic reaction to objective environment but is jointly built by media communication mechanism, the social tendency of audience and social mentality of group. As an intermediary, the media tend to focus on and enlarge some social problems and conflicts. Therefore, the risk management of government must face not only the challenges of social problems and conflicts but also medium risks.

The communication of network information represented by network rumor and network violence has increased the strength and destructiveness of network medium risks. As a result, it does harm to the order of network communication and disturbs present legal and social orders. Therefore, it is necessary to innovate the concept and idea of network legal supervision to cut down the network medium risks.

First of all, strictly distinguish the amount of communication of network information and the social harmful outcome of network communication, and treat harmful outcome created by network communication on real society as factual basis of legal supervision. After network communication transforms to serious social problems, only can the motivation of network communication (i.e., network infringement of right, the network crime motivation) and social destructiveness of network communication be found, behavior of network communication can be legally defined. If the computer-mediated communication doesn't bring in serious social outcome, for example, to use personal communication tools such as e-mail, QQ, wechat and so on to spread violence information, eroticism information and sensitive social information, it will not burden legal duties. If the medium social consequence and behavior of network communication have a certain evidence chain of cause and effect. For example, one person was subject to an attack of network violence in the affairs of network violence, but it is difficult for him to find out infringer to apply the claim of right infringement, the behavior of network communication didn't undertake the legal obligations.

The network communication is different from real social activities and difficult to form correspondingly the relationship of strong cause and effect with the consequence of the real society. Take the network infringement as an example, according to cases of network infringement, the harm to people's right of reputation and right of privacy made by network infringement has far exceeded the consequence of infringement of reputation and infringement of privacy. For example, Song Zude published the defamatory blog about Xie Jin, a Chinese famous director, after he died. This blog got a click-through rate of more than one million times. If all the consequences of infringement are attributed to original net placard, but never punish or give a lesser punishment to those who copy net placard, the corresponding relationship between the behavior of network infringement and the consequence of infringement. Sometimes, the effect of network opinion leader or network Big V which represents very important persons in network has far exceeded the originator of net placard. From the point of view of network group events and network infringement cases, the original net 
placard always tend to be like a stone dropped into the sea without echo after it is published. But when it is copied or recommended by network opinion leader or network Big V, it will fast develop and arise serious social consequence. Therefore, the middle links of network communication, like the network copier, the network clicker, the network opinion leader and so on are the indispensible important links in network medium risks and must be brought into the scale of network legal reputation.

However, both network lawmaking and network law enforcement want to treat quantification as the standard to measure the network infringement and network crime to strengthen the operability of law. But in this way, it will turn the cause-effect relationship of the behavior of network infringement and network crime and their outcome, which easily arises over-enforcement of law. For example, Provision One in Article Two of Interpretation of Some Issues concerning the Application of Law for the Trial of Criminal Cases on Defamation and so on with the Internet made by Supreme People's Court and Supreme People's Procuratorate has stated that according to criminal law "circumstances of aggravation" refers to the situation where the same defamatory information was clicked and browsed up to more than five thousand times or transmitted up to more than five hundred times. The number of "being clicked and browsed" or "being transmitted" can't directly form the basis for resulting in defamation. Logically speaking, the defamatory information can't be confirmed to be defamatory in advance, but need to be confirmed by the basis of the number of "being clicked and browsed" or "being transmitted". The defamatory information is not afterwards confirmed to be defamatory, but it needs the number of "being clicked and browsed" or "being transmitted" as a secondary evidence. Therefore, one information which is uncertain to be confirmed to be defamatory should be judged mainly by considering whether it leads to serious social consequence. For example, it makes the victims or their relatives become insane or harm or kill themselves, or it arises group events and confusion of the public order. It can't be judged by considering the number of "being clicked and browsed" or "being transmitted". Otherwise, it will easily produce over-enforcement of law made by law enforcement agency's behavior of simply quoting this provision. Shortly after this judicial interpretation mentioned above was published, Yang Hui, a student in the third year of junior middle school in Zhang Chuan County of Gansu Province, was criminally arrested by the police as a suspect involved in the aggressive crime, because he expressed his doubt about the abnormal death of one man in his county having conspiracy. This case caused the public opinion's worriment about the police's abuse of the public right. Yang Hui also became the first person who was punished for criminal detention because of transmitting information over five hundred times, after the Supreme People's Court and Supreme People made the judicial interpretation on network speech. Later, Yang Hui was punished for the administrative detention and then released. With discontentment of the punishment, he has already supposed administrative reconsideration and apply for state compensation. This case has told us: in network legal supervision, simply regarding the amount of information in network communication as the standard of law enforcement should not be scientific and rigorous.

Secondly, distinguish the communication motive of network disseminator, consider legal standards of being intentional and unintentional to confirm the legal responsibilities to be burdened. In the real society, people who acted the behaviors of infringement or crime could anticipate what the behaviors of infringement or crime may cause, which meant that they could anticipate or guess the possible social outcomes caused by the behavior. Therefore, with regard to the traditional behaviors of infringement or crime, motive and result has presented strong corresponding relationship. But in the network society, the network disseminators are difficult to make a precise anticipation of social consequence made by the behavior of communication. Even the 
behavior of communication is done in kindness, it also probably produces serious social outcomes. For example, after the big earthquake in Japan, the netizens disseminated the information of the seawater being polluted, which caused the panic purchase of salt. Therefore, it is significant to strictly distinguish the network intentional communication and network unintentional communication for legal supervision on network rumor and network violence information.

Network rumor, network violence information has the characteristics of spreading widely and repeatedly, which provides basis of distinguishing intentional communication and unintentional communication on law. Firstly, if communicator repeatedly disseminates the same or the similar information, he should be confirmed to intentionally communicate. Article Two, Provision Three in Interpretation of Some Issues concerning the Application of Law for the Trial of Criminal Cases on Defamation and so on with the Internet made by the Supreme People's Court and the Supreme People's Procuratorate states the situation where one who was once administratively punished for defamation defamed others again belongs to what the provision states. For example, some network Big V, network opinion leaders disclosed others' privacy information repeatedly using the way of seeking evidence which can be defined as the network intentional communication. For another example, some bloggers disclosed other's privacy and defame others for the amount of clicking and still continue doing this after he was sentenced to the network infringement, which can be defined as the network intentional communication. Secondly, after the authorities or persons concerned disclosed the truth, they still spread confusing information even rumors, which can be defined as the network intentional communication. At present, those events about the public departments and public officers which are concerned with corruption, wealth and public power easily cause network attention, even evolve in network group events. Search the Internet with the key words, such as "the most famous", "sky-high price" and so on, you will find various network public opinion events, like "the most famous government official in county level's villas in the middle region of China", "the most famous official jargon", "the most famous government official's disclosure", "the most famous service notification", "the most famous official seal", "the managing director with sky-high price cigarette", "the senior executive with sky-high price salary", "the secretary of county Party committees with sky-high price watch", "the sky-high price bill of official funds" and so on. At beginning of those public events, the fact of them was not clear and the government departments didn't handle them immediately. While, in order to get known the facts, people communicated and discussed with each other on the Internet. It would cause a false report in its circulation. If the authorities got involved in investigation and then disclosed the facts, and the person concerned also express the information to sweep away the rumors, some netizens still continued to spread the confusing information. This behavior of communication can be confirmed as the intentional communication. Thirdly, those network rumor and network violence information which obviously disobey the common sense can be confirmed as intentional communication behavior. Network rumor and network violence information is so complex and various that it is hard to judge whether it is true or false according to common sense. For example, whether the GM food is harmful to body. How far the high-speed rail is away from the residential area would be safe for the residents' health and so on. However, more and more network information can be judged its truth and falseness by common sense. Therefore, those communicators who already know the information's truth and falseness still spread it on the Internet can be confirmed as the intentional communication.

Thirdly, distinguish the sensitivity and harmfulness of the network information to confirm the legal responsibilities of the communicators. As the important source of jeopardizing social order, network rumor and 
network fake information would trigger network group events. But the information sensitivity of network rumor and network fake information differs widely. Some network information is so sensitive that it would harm the social public order after it is spread. Some network information belongs to the general information which is hard to harm the social public order even it is publicly spread. Therefore, to confirm the legal responsibilities of the communicators according to the sensitivity and harmfulness of the network information is the indispensable content of constructing the legal supervision mode of preventing network medium risks.

To distinguish the sensitivity and harmfulness of the network information to confirm the legal responsibilities of the communicators will not only effectively attack the communicators' dissemination behaviors of intentionally spreading network fake information to disrupt social order, but also protect netizen' right of communication and enhance netizens' responsible sense in communication so as to make them burden the legal duties for their own communication behaviors. On the one hand, if netizens spread the network information which is strictly banned by network laws and rules without authorization, he must burden legal duties, which means that the intentional communication of sensitive information must be with the attitude of zero-tolerance. For example, Article Three in Interpretation of Some Issues concerning the Application of Law for the Trial of Criminal Cases on Defamation and so on with the Internet made by the Supreme People's Court and the Supreme People's Procuratorate states one who uses network to defame others with one of the following situations should be recognized as "serious harm to social order and national interests" stated by the Article 246 of Criminal Law: One, triggering group events; Two, triggering public disorder; Three, triggering national, religional conflicts; Four, defaming more than one person which causes worse social effect; Five, being harmful to national image and seriously jeopardizing national interests; Six, causing worse international effect ; Seven, other situations which seriously harm to social order and national interests. Anyone who spreads the information mentioned above and causes corresponding social outcome must burden legal duties. On the other hand, don't limitlessly enlarge the scale of information banned by law. For the general network information communication, even it has effect on the government managing work and government image, it can't be the foundation for enlarging the scale of legal punishment and then it is punished. We must seek solutions from the views of government work and social administration. In recent years, the events like arresting across the provinces, the crime of defaming government only harm the authority of government and make the government's abusing public right become burning point of network medium risks.

\section{References}

Dai, Y. (2011). An interpretation of the we-media from the perspective of communication studies. Research on Journalism and Communication, 5, 4-11 .

Li, H. (2010). The transformation of media supervision mode under media convergence. News Lovers, 9, 12-13.

Tuo, J. (2010). Media risks and prevention under mimicry environment. News Knowledge, 2, 38-40.

Yin, Y., \& Liu, R. (2010). The global vision and Chinese characteristics of new media development-The development situation and advanced problems of China new media in 2009. In Y. Yin (Ed.), New Media Blue Book: China New Media Development Report (p. 5). Social Sciences Publishing House. 